\title{
HERNÁN CORTÉS SEGÚN NEIL YOUNG: UNA APROXIMACIÓN DESDE LA SOCIOLOGÍA DEL CONOCIMIENTO A UN CASO PARADIGMÁTICO DE DISTORSIÓN COGNITIVA
}

\author{
José Luis Palacios Gómez* \\ "La mentira es la más poderosa de las fuerzas de la historia" \\ J.F. Revel, El conocimiento inútil
}

\section{RESUMEN}

En este artículo se lleva a cabo una crítica del mito del buen salvaje en tanto que distorsión cognitiva, representada paradigmáticamente en una composición del músico Neil Young sobre la figura de Hernán Cortés. Se utilizan como herramientas para realizar esta crítica destacadas aportaciones de la filosofía, la psicología social y la sociología del conocimiento, especialmente la elaborada por P.L. Berger. Se muestran la inconsistencia del mito y sus anclajes y utilidades ideológicos y se concluye que una de las principales funciones de la sociología es desenmascarar falsas descripciones y explicaciones del mundo social.

\section{PALABRAS CLAVE}

Mito, distorsión cognitiva, ideología, sociología del conocimiento

\begin{abstract}
In this article we realize a critical approach to the good savage myth as a cognitive distortion, paradigmatically represented by a Neil Young's musical composition on Hernan Cortez figure. We use as a tool to do that criticism some relevant contributions from philosophy, social psychology and sociology of knowledge, specially that one elaborated by P.L. Berger. It's shown myth inconsistence and their ideological supports and utilities and we conclude that one of the main functions of sociology is to unmask both descriptions and explanations of social world.
\end{abstract}

\section{KEY WORDS}

Myth, cognitive distortion, ideology, sociology of knowledge

\footnotetext{
* Profesor de Sociología de la Universidad Complutense de Madrid.
} 


\section{INTRODUCCIÓN}

Recientemente se estrenó en las salas cinematográficas la que posiblemente sea la mejor película dirigida por Mel Gibson, Apocalypto. En síntesis, la cinta narra las vicisitudes de un indio maya (Garra de Jaguar) cuyo poblado es asaltado por otros mayas, que le toman como cautivo, junto con otros miembros de su tribu, y es llevado a una ciudad de los captores con objeto de sacrificarlo a los dioses en sangriento ritual apaciguador; nuestro héroe consigue escapar y, aunque ferozmente perseguido, regresar a su poblado donde le aguardan escondidos su esposa y su hijo; la llegada providencial de un navío con españoles le salva definitivamente de ser muerto por sus perseguidores; él y su pequeña familia se adentran en la selva a comenzar, esperanzados, una nueva vida.

La visión de esta emocionante película y la reacción negativa de algunos que han criticado ${ }^{1}$ la supuesta tergiversación de la idílica vida que llevaban los indios del Yucatán hasta la llegada de los conquistadores, nos ha hecho recordar una famosa canción que el músico canadiense de pop-folk-rock Neil Young grabó hace ahora algo más de treinta años. La canción, una de las nueve que contenía el disco Zuma ${ }^{2}$ llevaba el escasamente equívoco título de Cortez, the Killer (Cortés, el asesino) y presentaba, abrigado por una excelente música, el que probablemente sea el mayor conjunto de falsedades que en unas pocas líneas se haya escrito nunca sobre Hernán Cortés y sobre los indios mexicas y su forma de vida. La distorsión de la realidad que hacía Young no se limitaba al falseamiento de un ambiente sociocultural y de unos hechos acontecidos hace cinco siglos, sino que alcanzaba a las conclusiones cognitivas que de esa "lectura" de los "hechos" se derivaban. Distorsión, además, que entroncaba -y entronca- con una visión más amplia, con pretensiones omniabarcantes, del doxa de ciertos grupos sociales sobre cómo es el mundo social, que es más bien un "deber ser" construido, precisamente, sobre frecuentes tergiversaciones históricas.

Cabría poner reparos a la idea de que la película Apocalypto y la canción Cortez mantengan alguna clase de asociación vigente, ya que la primera es muy reciente y la segunda tiene ya una antigüedad respetable. Es cierto que entre los dos productos culturales median los años e importantes cambios y transformaciones sociales, pero sostenemos aquí que ambos guardan una clara relación en términos cognitivos: Cortez reafirma el mito del buen salvaje y Apocalypto lo cuestiona con contundencia, es su contrapunto. Son dos manifestaciones culturales que se hallan vinculadas porque se niegan mutuamente; son antitéticas y, por tanto, mantienen una relación conceptual innegable y en absoluto artificiosa que admite una aproximación analítica desde la filosofía, la sociología y otras disciplinas afines.

Por otra parte, los productos culturales que aluden a Cortés, generalmente con un enfoque muy peyorativo, han seguido apareciendo y mostrándose al gran público sin solución de continuidad desde que el Cortez de Young salió al mercado hasta ahora. Dos ejemplos, entre muchos, son las bien recientes películas La ruta 
hacia El Dorado (2000) y Piratas del Caribe: la maldición de la Perla Negra (2003), con difusión a escala planetaria ${ }^{\mathrm{i}}$. En la primera, de animación, aparece un ecuestre Cortés perverso y temible que busca el mítico Dorado (lo cual es un disparate, porque el mito de El Dorado surge después de la conquista de México y en el ámbito de Sudamérica, en la que nunca estuvo Cortés); en la segunda, un elemento fundamental de la trama es un cofre lleno de monedas de oro con caracteres pretendidamente "aztecas" que constituye "el tesoro de Cortés" (nuevo disparate, porque ningún tesoro de Cortés podía estar compuesto de monedas aztecas, por la sencilla razón de que los aztecas desconocían el dinero y practicaban el trueque o utilizaban semillas de cacao como moneda). Además, la difusión del Cortez de Young no se circunscribe al momento en que se publicó, pues se ha seguido escuchando continuamente hasta la fecha gracias al hecho de que Zuma se ha reeditado varias veces y a la circunstancia de que es una de las canciones del músico más populares entre sus seguidores ${ }^{4}$.

No contemplamos este Cortez, por tanto, como una simple vieja canción pop con una letra disparatada, lo cual sería completamente irrelevante, sino como una manifestación paradigmática de una concepción ideológica subyacente -un mitoque puede estudiarse en el plano teórico, pero también a través de sus productos culturales. Pero, además, si relacionamos Apocalypto y Cortez es porque tratan de lo mismo, del mismo mito ideológico, aunque lo expresan de modo antinómico: no en vano la vinculación de estos términos en cualquier buscador de Internet produce miles de "páginas" en las que ambos se asocian de una manera u otra.

Nuestra aproximación crítica al Cortez de Young cobra la forma de un estudio de caso de la mitología del buen salvaje. Es un análisis, desde la óptica de la sociología del conocimiento, de lo que entendemos como un ejemplo típico de distorsión cognitiva. Primero efectuamos un análisis sucinto pero pormenorizado de la letra de la canción desde una perspectiva histórica, con objeto de poner de relieve los errores y falsedades que contiene. Después nos aproximamos a los elementos cognitivos que laten en la misma utilizando recursos teóricos e interpretativos, tomados sobre todo de la psicología social y la sociología, que permiten comprender, en nuestra opinión, no solamente el fundamento tout court de la distorsión cognitiva, sino sus implicaciones sociopolíticas y sus conexiones con una concepción general del mundo social.

\section{LA LETRA DE UNA CANCIÓN Y LA REALIDAD HISTÓRICA: BREVE CRÍTICA HISTORIOGRÁFICA}

Comencemos por recordar la letra original de la canción en inglés y su traducción al español (figura 1). 


\section{Figura 1}

He came dancing across the water

With his galleons and guns

Looking for a new world

And a palace in the sun

On the shore was Montezuma

With his coca leaves and pearls.

In his halls hi often wandered

With the secrets of the world

And his subjects gathered 'round him

Like the leaves around a tree

With their clothes of many colour

For the angry gods to see

And the women all were beautiful

And the men stood straight and strong

They offered life in sacrifice

So that others could go on

Hate was just a legend

And war was never known

The people worked together

And they lifted many stones.

And they carried them to the flatlands

But they died along the way

And they built up with their bare hands

What we still can't do today.

And I know she's living there

And she loves me to this day

I still can't remember when

Or how I lost my way.

He came dancing across the water

Cortez, Cortez

What a killer.
Vino danzando por el agua

Con sus galeones y sus armas

Buscando un mundo nuevo

$Y$ un palacio al sol

En la playa estaba Montezuma

Con sus hojas de coca y sus perlas.

En sus salones se preguntaba a menudo

Sobre los secretos del mundo

Y sus súbditos le rodeaban

Como las hojas alrededor de un árbol

Con sus vestidos de muchos colores

Para que los enfadados dioses les viesen

Y las mujeres eran todas bellas

$Y$ los hombres rectos y fuertes

Ofrecían sus vidas en sacrificio

Para que los otros pudieran seguir

El odio era sólo una leyenda

Y la guerra nunca se había conocido

La gente trabajaba junta

Y levantaban muchas piedras.

Y las llevaban a las llanuras

Pero morían por el camino

$Y$ construyeron con sus manos desnudas

Lo que aún hoy no podemos hacer.

Y sé que ella vive allí

$Y$ que me ama hasta hoy

Pero no puedo recordar cuándo

O cómo perdí mi camino.

Vino danzando por el agua

Cortés, Cortés

Qué asesino.

A la vista está que la letra de esta canción no es un prodigio lírico, aunque ciertamente suena mejor en inglés que en español. Pero esto, naturalmente, es aquí lo de menos, pues de lo que se trata es de mostrar en qué medida el contenido se corresponde con la realidad. Estudiemos cada estrofa separadamente para llevar a cabo un mejor análisis.

Sólo metafóricamente podemos imaginarnos a Cortés brincando por las aguas para llegar a Tabasco, desde Cuba, después de su breve paso por Cozumel. En todo caso, Cortés no navegaba en galeones, pues estos eran barcos de altura que no se utilizaban entonces en aquella parte del mundo ${ }^{5}$. Usó naves de mucho menor porte, tipo nao o bergantín 6 . El "galeón de Indias", idealizado en las películas como nave enorme y lujosa, es probablemente la idea que Young tiene en mente, tal vez 
extraída de las películas de piratas, pero estas embarcaciones no se comenzaron a usar hasta mucho después de la conquista de México y desde luego con fines bien distintos a los de la exploración. Primer error, pues, del texto de la canción. Menor, aparentemente, pero ya indicativo de que Young maneja arquetipos y no datos cuando construye la letra de Cortez. Lo de "buscar un nuevo mundo y un palacio al sol" también es inexacto, a la luz de lo que sabemos sobre los proyectos y la personalidad de Cortés ${ }^{7}$, pero dejémoslo ahí de momento.

En la costa no estaba "Montezuma". En realidad, se llamaba Moctezuma Xocoyoatzin o Moctezuma el Joven (o Moteczuhoma, si se quiere seguir la versión náhuatl), pero a Young le debe sonar más lo de Montezuma porque se parece a Monterrey o Montalbán, que le resultarían más familiares ${ }^{8}$. Y desde luego, la ciudad donde residía Moctezuma, Tenochtitlán, estaba muy lejos del mar (a más de trescientos kilómetros), en donde hoy se levanta la ciudad de México. El emperador (Hueytlaotani) azteca, además, jamás se acercó a la costa, ni para parlamentar con Cortés (cometido para el que enviaba a sus representantes) ni para otra cosa (aunque es posible que en sus años de jefe guerrero hubiese llegado hasta el Caribe). Lo de que se entretenía con "sus hojas de coca y sus perlas" es, sencillamente, un dislate: los mexicas ni cultivaban ni usaban la coca, al contrario que los incas y otros pueblos andinos, con los que Young probablemente les confunde (aunque sí usaban otras substancias psicotrópicas, generalmente derivadas de diversos hongos); y las perlas, si algunas tenían Moctezuma y sus súbditos, debían de ser extremadamente raras, a juzgar por el hecho de que nunca se mencionaban en las descripciones de los tesoros aztecas ${ }^{9}$. El que Moctezuma se preguntase asombrado por los secretos del mundo seguramente se corresponde con la verdad: como sumo sacerdote, estaba inmerso en los entresijos, ciertamente "asombrosos" de su religión, tal como la profecía del retorno de Quetzalcoatl, y las sangrías y autolesiones rituales y la eventual ingesta de drogas alucinógenas debían de potenciar su capacidad de "asombrarse".

Rodeaban a Moctezuma sus súbditos, efectivamente, al menos en el sentido poético de la expresión, pero tal muestra de afecto y devoción provenía sobre todo de los propios mexicas, ya que los otros súbditos -chalcas, tepanecas, cholultecas, totonacas, etc.-, sujetos al yugo imperial por la fuerza, más bien le temían y le odiaban ${ }^{10}$. El pueblo llano mexica, por otra parte, raramente usaba ropa de "muchos colores", si no era en ocasiones muy especiales (vestía habitualmente prendas de fibra de maguey y de algodón crudo) ${ }^{11}$, aunque, desde luego, algunos de sus dioses, como el terrible Huitzilopochtli, sí parecía que estaban con frecuencia muy enfadados.

Es dudoso que todas las mexicas fuesen bellas, por aquello de la habitual distribución gaussiana de las características de las personas, pero sí parece que algunas lo eran, al menos si nos atenemos a las valoraciones de algunos de los conquistadores, quienes, por otra parte, no estaban acompañados de muchas europeas con las que establecer exigentes comparaciones. De todos modos, para 
gustos se hicieron los colores, sin perjuicio de que ningún contemporáneo -y tampoco Young- puede hacerse una idea de cómo eran las mujeres mexicas si no es a la vista de las actuales indígenas que aún pueblan México ${ }^{12}$. Por la misma razón estadística antes señalada, también es dudoso que todos los hombres fuesen rectos sea en el sentido físico o en el moral- y fuertes. De lo último, ni los conquistadores (que tenían buenas razones para reparar en ello) ni los cronistas se hacen eco, y de lo primero cabe destacar el hecho de que los mexicas contaban con un muy riguroso sistema penal para castigar faltas y delitos ${ }^{13}$ (prueba indudable de que existían) según su idea de comportamiento correcto, dejando ahora a un lado el testimonio de los españoles sobre las tretas y añagazas de los indios para perjudicarles (algo natural, claro, como estrategia bélica). Finalmente, y sobre todo en la época de esplendor del imperio azteca, los mexicas no solían ofrecer su vida en sacrificio, sino que gustaban más de ofrecer la vida de "otros", a quienes efectivamente sacrificaban para aplacar la ira de los dioses, para favorecer las cosechas, para aterrorizar a sus enemigos y, eventualmente, para comérselos ${ }^{14}$.

La siguiente estrofa contiene ciertamente la mayor de las falsedades que trufan la letra de la canción: el odio era sólo una leyenda y la guerra nunca fue conocida. Precisamente el imperio azteca (como todos los demás, por otra parte) se había construido sobre la guerra y una de las características principales de los mexicas como pueblo era su acendrado espíritu guerrero. Al menos desde el siglo XIV estaban "siempre" en guerra ${ }^{15}$ merced a la cual lograban su dominio sobre los otros pueblos, los tributos que enriquecían a Tenochtitlán (y a las otras ciudades lacustres aliadas) y los prisioneros que sacrificaban a sus dioses. Es más, cuando a finales del XV llegaron a la conclusión de que quedaba poco por conquistar (ya que los tabascos y los chichimecas parecían enemigos irreductibles) y que por tanto se corría el riesgo de que la guerra desapareciese, instituyeron una curiosa práctica bélica: las guerras floridas ${ }^{16}$, especie de competiciones militares con otros pueblos que, no obstante, poseían un marcado realismo, ya que en ellas moría buena parte de los competidores y se hacían prisioneros ... que después eran convenientemente sacrificados a los dioses. Por otra parte, los niños mexicas eran instruidos desde temprana edad en las artes militares -un tanto al modo de los espartanos- y el morir en la guerra se consideraba un alto honor ${ }^{17}$ Esto en lo que respecta a los mexicas, pero que puede hacerse extensible a casi todos los demás pueblos indígenas mesoamericanos, que mantenían continuos conflictos bélicos con sus vecinos, conflictos que también incluían la toma de prisioneros y, al menos ocasionalmente, su sacrificio en el altar de la correspondiente deidad ${ }^{18}$. Entendemos que Young está siempre refiriéndose en su canción a los mexicas, pero por si en algún momento los puede confundir con los mayas, cabe recordar que estos, a la llegada de los españoles, también se hallaban inmersos en permanentes guerras tribales y que practicaban el sacrificio de prisioneros ${ }^{19}$ (circunstancia que recoge la película Apocalypto y que constituye un eje de su trama, aunque la "metodología" sacrificial parece tomada de la que se conoce que practicaban los mexicas). El resto de la 
estrofa -la gente trabajaba junta y levantaba muchas "piedras"- responde a la verdad, pero no la cuenta toda: si bien las clases populares trabajaban frecuentemente en las obras públicas (que incluían los palacios de los dirigentes), se empleaban asimismo gran cantidad de esclavos como mano de obra ${ }^{20}$. En todo caso, y aunque los propios conquistadores se hicieron eco de la magnificencia de algunos edificios (como el dedicado a Huitzilopochtli, para cuya inauguración en 1487 se sacrificaron, probablemente, varias decenas de miles de prisioneros ${ }^{21}$ ), cuando Young señala que esas construcciones "aún hoy nosotros no podemos hacerlas" parece estar pensando más en la gran pirámide de Keops o, en el mejor de los casos, en la de Teotihuacan, que, sin embargo, no construyeron los aztecas, y que, de cualquier modo, es obvio que sí se podrían construir hoy (independientemente de que constituyese una empresa desmesurada en coste y energía). El que mientras se erigían tales edificios muriesen muchas personas es algo que, aunque no sabemos con certeza, no habría de extrañarnos.

Cierra Young su canto con un verso que no parece guardar ninguna relación con el resto: "Y sé que ella vive allí ...". Tal vez le faltaba una estrofa para terminar la canción e ideó una de jaez romántico, que sonaba bien aunque no casara con las otras; quizás había tenido una novia mexicana y aprovechaba para dedicarle un recuerdo; o se había identificado hasta tal punto con los indios mexicas que fantaseaba con un encuentro extratemporal con una bella azteca. No sabemos en verdad cuándo o cómo perdió su camino.

Finalmente, el verso lapidario: "Cortés, Cortés, qué asesino". Pero, ¿fue Cortés un "asesino", en el sentido neta y mayúsculamente peyorativo que se le da aquí a la palabra? No caben dudas sobre el hecho documentado de que Hernán Cortés dio muerte a un buen número de enemigos en los múltiples combates habidos durante la conquista de México, y caben pocas respecto de que ordenó matar a otros por considerarlos rebeldes o traidores; algún otro, además, fue muerto por orden suya por resultar políticamente inconveniente que siguiera con vida (el caso más célebre es el de Cuauhtémoc, en 1525, tras ser descubierta una presunta conspiración contra Cortés en la que participó). Sin embargo, los relatos de sus coetáneos y las más solventes interpretaciones de su personalidad y de su conducta que se han hecho en nuestra época nos alejan de la idea de un hombre cruel y perversamente homicida: no sólo nos pintan a un Cortés más inclinado a la política que a la violencia, sino a alguien que cuando practica esta última suele hacerlo con moderación infrecuente para los usos de aquellos tiempos ${ }^{22}$. Su preferencia por el pacto antes que por el combate, su estrategia de imponerse más por el convencimiento que por la mera fuerza, su pesadumbre por la destrucción causada y la miseria que observa entre sus vencidos enemigos ${ }^{23}$, no concuerdan con el estereotipo de hombre malvado con el que se le ha querido identificar. Si cometió crímenes, no parece que lo hiciese por vocación vesánica, sino que consideró que sus acciones venían obligadas por la situación y, en todo caso, justificadas por el fin superior de servir al emperador Carlos y a la causa de Cristo. Es obvio que buscaba 
también su propio beneficio, más en el orden del honor y del prestigio que en el material, pero fue probablemente el más legalista, el más ilustrado y hoy diríamos el más "humanista" de todos los conquistadores españoles. Si algunos conquistadores merecieron el calificativo de "asesino" sin paliativos, Hernán Cortés no figura en esa relación, especialmente si se contextualiza en la época y en la circunstancia su actuación. En cualquier caso, si pese a todo se sigue considerando a Cortés un asesino, ¿cómo habría que considerar no ya sólo a otros personajes históricos que realizaron acciones semejantes -Aníbal, Saladino, Gengis Khan, etc.- sino al propio Moctezuma, de quien se refiere ${ }^{24}$ por ejemplo, que ordenó asesinar a las familias enteras de varios nigromantes mexicas porque estos no eran capaces de interpretar ciertos agüeros?

\section{EL MITO Y LA REALIDAD: BREVE CRÍTICA SOCIOCOGNOSCITIVA}

Un excelente libro de Steve Pinker, La tabla rasa ${ }^{25}$, nos señala que son tres los obstáculos socioculturales de nuestra época para alcanzar un conocimiento auténticamente científico de los fenómenos del mundo: el mito de la tabla rasa, el mito del fantasma en la máquina y el mito del buen salvaje. El primero se refiere a la idea sociologista, de raíz aristotélica, de que la vida social, la experiencia, la socialización constituyen la única matriz del comportamiento de las personas; el segundo se refiere a que es la divinidad la que orienta o da finalidad a nuestra conducta, que en consecuencia no puede ser explicada sólo en meros términos materiales; el tercero, en fin, se refiere a la creencia roussoniana de que el hombre es bueno por naturaleza y en estado de naturaleza, siendo la sociedad y la civilización lo que le corrompe. Es evidente que la canción de Neil Young que hemos comentado es un ejemplo superlativo del mito del buen salvaje (aunque tanto los mexicas como los mayas habían trascendido sobradamente el estadio que técnicamente conocemos como "salvajismo"): los indígenas americanos eran buenos, pacíficos y felices (y bellos, no se olvide) hasta que llegaron los malvados europeos (españoles, para empeorar las cosas) a destruir o pervertir (lo que es peor) aquel paraíso que, como el bíblico, estaba exento de todos los vicios de nuestra civilización. ¿Cómo es posible sostener tal cosa a la luz de la amplísima información que disponemos sobre la vida de los más diversos pueblos a lo largo de la historia? ¿No nos ilustran los datos históricos -y también los antropológicos y aun los arqueológicos- de todo lo contrario? ¿No se repara en que no se conoce pueblo, cultura o civilización que no haya practicado la guerra de una u otra forma y que todos los imperios que han existido -y no sólo el azteca o el español- se han constituido y han ejercido su dominio merced a la fuerza? Que los españoles subyugaron a los mexicas es un dato tan innegable como que estos subyugaron a otras naciones indígenas y que tanto en uno como en otro caso tal dominación se basaba en el uso de la violencia. Rechazar esta evidencia parece que, en principio, 
solamente puede tener como causa la ignorancia o la mala fe o una combinación de ambas cosas.

No sabemos el nivel de información histórica que tendría Neil Young cuando escribió su Cortez, pero aunque todo hace pensar que era muy bajo, resulta difícil creer que lo fuera tanto como para desconocer estas obviedades: se puede confundir Machu Picchu con Tikal o no saber nada de la existencia de los tlaxcaltecas o de los mochicas, pero ignorar completamente las fricciones, conflictos y guerras entre la gran variedad de pueblos y culturas del continente americano y, sobre todo, el hecho de que frecuentemente unos acabaron literalmente- con otros, se nos antoja excesivo para cualquier occidental que haya asistido a la escuela y especialmente para uno que compone y divulga una canción sobre el tema. La cuestión aquí, por consiguiente, seguramente no es algo que tiene que ver tanto con la información, aunque juegue su papel, como con la ideología: el contenido de la canción y su estilo cognitivo nos hablan de una toma de posición apriorística basada en la asignación de propiedades positivas a un grupo social y de propiedades negativas a otro. Es una concepción dualista y maniquea sobre el mundo y la sociedad: mientras que unos -los mexicas, en este caso- son los buenos, otros -los españoles- son los malos; pero "buenos" y "malos" en términos absolutos, como representaciones totales y excluyentes de la bondad y la maldad; no caben medias tintas.

Ciertamente, lo que menos importa en relación con esto es la particular concepción de Neil Young sobre el asunto discutido: es sobre todo un buen músico, pero alguien perfectamente irrelevante en los campos de la historia o la antropología. Lo significativo es que en Cortez encarna el sostenimiento y reproducción de un discurso construido sobre mitos y falsedades que, sin embargo, comparten millones de personas, las que escucharon y cantaron la canción sin parpadear y las que aun no habiéndola escuchado también comparten en líneas generales su contenido o, al menos, su intención.

Cortez es un caso paradigmático de distorsión cognitiva en el que al mito del buen salvaje se le une otro factor de gran densidad ideológica: la teoría del chivo expiatorio ${ }^{26}$, que tantas veces se ha refrendado empíricamente, así en el curso de la historia como en la vida cotidiana. Cortés es, sin duda, un magnífico chivo expiatorio; representa, como probablemente ningún otro conquistador (tal vez con la excepción de Pizarro), al occidental destructor de arcadias felices, mancillador de la inocencia primigenia, feroz depredador de las riquezas (espirituales y materiales) limpiamente atesoradas por una comunidad libre y bondadosa. Reúne todas las características del hombre civilizado malvado: arrogante, por su etnocentrismo; materialista, por despreciar la espiritualidad de otra cultura; rapaz, por su afán desmedido de lucro personal; cruel, por su inclemencia con el enemigo. Y además, coartada, aunque insólita, para explicar las carencias estructurales de algunas sociedades americanas en nuestros días (transcurridos cinco siglos desde la 
conquista y dos siglos después de acabada la colonia). Utilísima figura la del chivo expiatorio, receptáculo sin fondo donde arrojar los pecados propios y ajenos.

Si consideramos que el mito del buen salvaje es completamente falso (como las acusaciones a Cortés en mayor o menor medida), no queda sino asombrarse, como Moctezuma con los secretos del mundo, de que tenga tanto predicamento. Pero es que esta distorsión cognitiva tiene algunas apoyaturas de tremenda funcionalidad psicosociológica: recordemos al respecto, por ejemplo, el celebérrimo teorema de W.I. Thomas ${ }^{27}$ y la teoría de la disonancia cognitiva de L. Festinger ${ }^{28}$. Por el primero sabemos que, en último término, poco importa que algo sea o no cierto, lo fundamental es que la gente lo crea, pues lo real es la consecuencia derivada de dicha creencia. Por la segunda sabemos que cuando la realidad contradice una creencia muchos se ven tentados a ignorar la realidad o a reelaborarla para evitar la incómoda disonancia entre lo real y lo pensado. Parece muy pertinente traer ambas aportaciones teóricas a colación, porque podrían explicar satisfactoriamente la causa de que quienes son ignorantes de los datos de las ciencias sociales sostengan el mito del buen salvaje, pero actúen (más bien opinen) como si no fuera un mito (teorema de Thomas), y de que quienes son "cultos" soslayen los datos o los tergiversen (teoría de Festinger).

Hay también otra interesante derivada teórica para explicar cómo resulta posible que a pesar de la abundancia y la solvencia de los datos, los "cultos" persistan en la defensa del mito: la teoría del resentimiento, sustanciada entre otros por Nietzsche y Weber ${ }^{29}$. La teoría postula, en síntesis, que la falta de correspondencia entre la realidad y un presunto destino merecido fabrica resentidos: yo merezco algo y sólo los demás son culpables de que no lo tenga. Esto explicaría que muchos resulten inmunes al dato, pues o el dato se acomoda a su "destino merecido" o simplemente es falso, mera confabulación de "los otros".

Otra aportación teórica interesante para el asunto que tratamos es el concepto de "mala fe", pero no en el sentido sartriano del término, sino en el común que se refiere a la "mala intención": en nuestro caso, a sostener algo que es falso pero a sabiendas de que es falso, simplemente por razones de estrategia -es la mentira que Sartre llamaba "mentira a secas", precisamente para diferenciarla de la mauvaise foi $^{30}$-, así que un "culto" defiende una falsedad no porque no sabe que lo es, sino porque conviene, a él, a su grupo, a su clase, defenderla. Es obvio que algunos que defienden el mito del buen salvaje y sus derivaciones lo hacen, siendo conscientes de su inconsistencia, porque es un mito que se compadece con determinados intereses morales, políticos, económicos o de otro tipo. A este respecto, es oportuno recoger el argumento de Vaca de Osma ${ }^{31}$ de que la figura de Cortés (falseada) fue utilizada como arma arrojadiza por los países enemigos de España, pues representaría el más vivo exponente de la famosa leyenda negra en su proyección indiana.

Pero, ¿qué sucede con los que no son ignorantes y tampoco tienen mala fe?, ¿cómo es posible que millones de personas medianamente informadas y con una 
inteligencia común sostengan discursos manifiestamente inconsistentes en términos de la veracidad de sus componentes? Es una cuestión compleja, pero probablemente puede en buena medida explicarse en virtud de los mecanismos sociocognoscitivos que estudia la sociología del conocimiento fenomenológica, especialmente la de corte bergeriano ${ }^{32}$ Porque es Berger (acompañado por Luckmann en una parte del recorrido) quien mejor ha explicado (en oportunísima síntesis, en nuestra opinión, de las teorías de Mead y Schultz, por un lado, y de Weber y Durkheim, por otro) el mecanismo por el que la realidad social se construye, se mantiene y cambia. Para la sociología del conocimiento bergeriana la realidad social es fruto de un proceso dialéctico en el que el individuo construye y re-construye la sociedad al tiempo que es construido y re-construido por ésta. El proceso consta de tres fases o momentos: externalización, objetivación e internalización ${ }^{33}$. Los individuos vuelcan al mundo, en el curso de su actividad vital, ideas, conceptos, saberes; cuando estos elementos cognoscitivos se repiten suficientemente se objetivizan, gracias a una suerte de sedimentación, y se transforman en saber social objetivado, en conocimiento socialmente disponible, formando determinadas concepciones del mundo (cosmovisiones, Weltanschauungen); y en un tercer momento, ese saber socialmente objetivado es asumido por los otros individuos (lo internalizan) merced a los procesos de socialización primaria (en la primera infancia) y secundaria (después de la primera infancia). Además, como el proceso es circular, lo internalizado se devuelve al mundo en una nueva externalización, que eventualmente puede objetivarse, etcétera. Las socializaciones secundarias pueden tener lugar a lo largo de toda la vida de un individuo (aunque disminuyen su probabilidad de ocurrencia con la edad) y en algunos casos incluso pueden producirse fenómenos de alternación $^{34}$, caracterizados por la asunción de concepciones del mundo radicalmente diferentes a la asumida hasta ese momento (son los fenómenos de conversión religiosa o ideológica que algunos experimentan). Pensamos que este proceso dialéctico entre la mente y la realidad social permite comprender el fenómeno cognoscitivo que aquí discutimos: la asunción de formas de pensamiento, de mentalidades, con relativa independencia de los hechos realmente acontecidos a los que aquellas se refieren, es el producto de una socialización secundaria por la cual determinados elementos eidéticos pasan a constituirse en saber social objetivado. En definitiva, el que millones de personas asuman, explícita o implícitamente, el mito del buen salvaje (y, en consecuencia, asuman que efectivamente, en el caso que nos ocupa, los mexicas habían construido -matices aparte- un inmaculado paraíso en la tierra y que Cortés y los occidentales lo destruyeron -ahora sin matices- sin justificación alguna, por pura perversidad) es un ejemplo de exitosa socialización secundaria cuyos factores de iniciación y mantenimiento son complejos pero identificables. Obviamente, no podemos aquí analizar en detalle todos los elementos y circunstancias que dan lugar y que sostienen este modelo de pensamiento, pero sí podemos esbozarlos sucintamente: el atractivo ingenuo del buenismo roussoniano, los efectos del 
movimiento contracultural (que en la fecha de composición del Cortez de Young 1975- eran por cierto muy notables), el naturalismo irenista ("ecologismo"), los movimientos revolucionarios anticapitalistas, la difusión de las filosofías y mitologías orientales (budismo, hinduismo, ...), el indigenismo, el marxismo mal digerido y, probablemente, el llamado "pensamiento débil" en general ${ }^{35}$ De manera que con estos mimbres se ha hecho este cesto, un cesto en el que caben las más mayúsculas falsedades siempre que encajen con alguno o con varios de los elementos cognitivos que lo constituyen (pero no necesariamente con todos, pues estos ni siquiera encajan bien entre sí: verbigracia, la concepción sociologista/ culturalista de la persona es antitética de la naturalista).

Por cierto que en relación con este asunto resulta de gran utilidad el concepto, también bergeriano, de paquete $\operatorname{cognitivo~}^{36}$, un conjunto de elementos cognitivos amalgamados que proporciona sentido a un ámbito de realidad más o menos extenso, con capacidad para dar un determinado significado a una experiencia vital y para informar un discurso sobre la misma. Estos paquetes son vehiculados por ciertos "portadores" ${ }^{\text {"37 }}$ (otro concepto empleado por Berger, con resonancias weberianas), como libros, películas, periódicos, discos y demás productos culturales, y también por televisiones, instituciones, universidades, escuelas, ..., que actúan como vectores de difusión, asentamiento, consolidación y conservación de un discurso interiorizado como visión del mundo. En la medida en que ese discurso se ha expandido y ha sido asumido por una buena parte de los productores y reproductores del conocimiento (cuyas filas nutren muchos reputados "intelectuales"), varias generaciones de occidentales han sido sometidas a un macroproceso de socialización que, como una lluvia fina pero constante, ha ido calando, casi inadvertidamente, en la mentalidad de millones de personas. Y hasta tal punto que, efectivamente, las ideas así imbuidas son percibidas por los individuos como propias ${ }^{38}$, formando además una especie de filtro que retiene la información disonante y convenientemente la deshecha ${ }^{39}$. Se diría que esta socialización tan exitosa opera como una vacuna: inmuniza, como un automatismo, sin necesidad de que se repare en ello, contra los ítems de la realidad que pudiesen poner en tela de juicio la forma de mentalidad que ha construido. Es ciertamente tan efectiva que sólo mediante una verdadera epojé (à la Husserl) puede ponerse en entredicho y ser evaluada en su pertinencia y su veracidad. A todo ello convendría añadir, probablemente, la incomodidad y el riesgo de actuar, e incluso de pensar, a contracorriente por parte de aquellos que eventualmente puedan sospechar que esta suerte de verdad oficial es un gigante con los pies de barro.

Puede incluso que algunos mitos, como este del buen salvaje, gocen de una inmerecida aceptación en virtud de su "pertinencia" estratégica dentro de ideologías más amplias que cuestionan y/o combaten otras ideologías, vinculadas a ciertos sistemas sociales (que asimismo son cuestionados y/o combatidos). Así, determinadas concepciones del mundo, o partes constitutivas de éstas, resultan valiosas para una forma ideológica concreta porque pueden ser utilizadas contra una 
ideología rival, resultando por tanto "funcionales" para socavarla. No es que el mito sea considerado veraz, sino que es "útil": sirve para perjudicar al enemigo y por eso se le acoge y potencia. Otra cosa es que, sin perjuicio de su utilidad para combatir ideologías rivales, el mito sea asumido como cierto, o al menos como creíble, por un grupo social como parte de su imaginario identitario y se defienda y difunda como "algo nuestro". Este aspecto del mito sería entonces una manifestación del fenómeno sociocognoscitivo que tan acertadamente calificó Mannheim como “distorsión doctrinal de las ideas" ${ }^{40}$, muy vinculado a la confrontación ideológica de carácter sociopolítico.

Por último, también parece pertinente considerar aquí la aproximación marxista a los "aparatos ideológicos" del estado ${ }^{41}$ (burgués) para comprender mejor el modo en que se articulan los elementos cognitivos de esa particular forma ideológica (mito) que es parte de una concepción del mundo más amplia. El postulado de que un modo de producción material precisa de mecanismos de reproducción ideológica para perpetuarse puede rescatarse para abundar en la idea de que un mito es susceptible de ser utilizado como un mecanismo de dominación sociopolítica. Así, una clase que controla los medios de producción ha de controlar también la producción de ideas para que sean acordes con dicho modo de producción (lo cual crearía una "falsa conciencia" en la clase desposeída del control de los medios de producción). Pues de forma semejante el grupo social que construye una ideología y pretende convertirla en ideología dominante articulará apropiados mecanismos de dominación ideológica -aparatos ideológicos- para perpetuarse como grupo dominante: así el mito opera como parte del complejo ideológico que se desarrolla con vocación de dominación cognitiva.

\section{A MODO DE CONCLUSIÓN}

Estas páginas en absoluto pretenden ser una hagiografía de Hernán Cortés ni una trivialización de las guerras de conquista que truncaron las culturas precolombinas. Los datos históricos son demasiado contundentes como para pensar siquiera tal cosa. Pero son contundentes en todos los sentidos: en el de desmitificar la idea de un Cortés arcangélico y en el de desmitificar la idea seráfica de una sociedad indígena provista de todas las virtudes de las que carece la sociedad occidental, antigua y contemporánea. Sin embargo, el mito del buen salvaje, representado tan burda como paradigmáticamente en el Cortez de Young, goza de buena salud contra toda evidencia. Toda vez que esto resultaba, prima facie, harto sorprendente, nos propusimos aquí dos tareas: poner de relieve por qué en este caso particular el mito no se tiene en pie y ensayar una explicación de cómo es posible que, a pesar de su manifiesta falsedad, tanta gente lo sostenga.

Lo primero, obviamente, resulta bien sencillo, pues basta con revisar algunas fuentes de la época y echar mano de unos pocos textos escogidos por su 
solvencia técnica, de entre los muchos que tratan el asunto, para dejar meridianamente claro que el mito es indefendible en términos científicos.

Lo segundo ciertamente es más complejo, porque presenta múltiples posibles facetas susceptibles de ser analizadas desde diferentes puntos de vista. Para ello hemos recurrido a las aportaciones de algunos autores que, desde distintas ópticas y disciplinas, han tratado el problema de la distorsión cognitiva, pues pensamos que efectivamente ésa y no otra es la naturaleza de la cuestión que se plantea y la razón de que pueda abordarse como un problema de sociología del conocimiento. Los ítems que aquí juegan no son, por consiguiente, algo que tenga que ver tanto con los hechos cuanto con su interpretación y manipulación, en diversos planos de conciencia. Evidentemente, es posible que muchas personas al desconocer los hechos históricos lleguen a conclusiones erróneas sobre la realidad (como se llegaba a conclusiones equivocadas sobre la transmisión de las enfermedades cuando no se sabía de la existencia de los microbios). Tendría así lugar una mixtificación de la realidad por mera ignorancia: en el caso que hemos considerado, ignorar, por ejemplo, el hecho de que los tlaxcaltecas (enemigos acérrimos de los mexicas y parcialmente sojuzgados por estos) se aliaron fielmente con Cortés, constituyendo un factor de primerísima importancia para que el conquistador alcanzase con éxito sus objetivos ${ }^{42}$ puede hacer que se malinterprete de manera fundamental la realidad de la conquista de México.

Pero el problema sociocognoscitivo que aquí hemos tratado tiene, en nuestra opinión, mucho mayor alcance; la ignorancia del dato es una parte del problema, pero en absoluto la más relevante. Fascina constatar que para una buena parte de los occidentales que sí conocen el "dato" éste se integra con facilidad en su acervo de conocimiento (que además tienen por fundamentado en los hallazgos de la ciencia), sin producir el menor chirrido cuando se articula con su visión tan decididamente favorable a los aztecas como decididamente condenatoria de Cortés. Hemos apuntado que la teoría de la disonancia cognitiva explicaría afortunadamente este fenómeno: bueno -nos dirán- puede que los tlaxcaltecas ayudasen de forma decisiva a Cortés, pero eso sucedió porque éste les engañó y finalmente les causó mayor mal que el que los aztecas les causaban. Y así volvemos al punto de partida, sin duda ni inquietud: los malos eran los conquistadores y los buenos los aztecas. También hemos esbozado otras formas intencionadas e instrumentales de construir distorsiones y de usarlas en provecho de intereses diversos. Pero, una vez más, lo sorprendente no es que los directamente interesados en sostener un mito lo sostengan (cual sería el caso de los indígenas), sino que otros, cuyos intereses objetivos generales como grupo resultan claramente perjudicados por el mito, también lo sostengan (en extraño ejercicio de masoquismo). Resulta difícil de explicar, por ejemplo, sin recurrir a un desmesurado afán de autocrítica o a un ejercicio de arrepentimiento y contrición que para otras cuestiones no se muestra tanto, que muchos españoles contemporáneos, a cuyo país es obvio que no le interesa aparecer (máxime si es 
inmerecidamente) como cruel destructor de inmaculados paraísos, asuman ciegamente y afirmen y propalen cuando se tercia que sin duda la Conquista es el más negro episodio de su Historia ${ }^{43}$, hecho del que avergonzarse eternamente y deudor de la más firme condena (y ello desde coordenadas morales actuales, sin aparentemente considerar que aquello ocurrió en una época en la que, por ejemplo, era comúnmente aceptado ¡comprar y vender “personas"!).

Hemos dado relieve especial a la existencia de una cosmovisión formada con una sorprendente amalgama de elementos eidéticos (roussonianos, anticapitalistas, "naturalistas", indigenistas, ...) que, en nuestra opinión, constituyen el caldo de cultivo en el que fermenta el mito del buen salvaje. Las personas que comparten esta particular cosmovisión (no necesariamente en todo: como Alfred Schutz apuntaba ${ }^{44}$ sólo en parte intersectan y se solapan las distintas realidades múltiples en que habitan los individuos) asumen el mito del buen salvaje por variados motivos, pero probablemente son los menos quienes lo hacen por falta de información veraz al respecto. Es más frecuente que ese mito se incorpore a la mentalidad subjetiva en virtud de factores cognitivos que tienen que ver con específicos intereses ideológicos conscientes o semiconscientes; por increíble que sea el mito, puede integrarse dentro del complejo ideológico porque resulta funcional, útil, especialmente como elemento de oposición ante la ideología rival (el capitalismo, el cristianismo, la cultura occidental, etc.). Por cierto que no es una reflexión inoportuna en este espacio considerar la tesis que sostiene Glucksmann ${ }^{45}$ de que uno de los conflictos fundamentales que existen en nuestra civilización es el que enfrenta a Occidente consigo mismo, el que opone a dos concepciones sociocognoscitivas: la que se identifica con nuestra cultura, aun con sus defectos, y la que se identifica con su negación y, tal vez indirecta pero objetivamente, con quienes la niegan (quizás por eso algunos de los que experimentaron gran vacío con la caída del sistema soviético están tentados de cubrirlo con el fundamentalismo islámico -pirueta surrealista donde las haya-). En todo caso, parece bien acertada la idea de Berger y Luckmann de otorgar a los "universos simbólicos" ${ }^{46}$ que poseen la capacidad de integrar diferentes "zonas de significado", el más alto poder de legitimación de una estructura cognitiva total, sin que para ello resulte en absoluto necesario que sus anclajes sean veraces.

Este es el tipo de mecanismo cognitivo que aquí opera, muy efectivamente, y que hemos tratado de esbozar analíticamente en estas páginas. Pero, por sorprendente que parezca, este fenómeno sociocognoscitivo no sólo ha recibido poca atención por parte de la ciencia social, sino que ésta es en cierta medida responsable de la distorsión cognitiva a la que aludimos: Pinker ha puesto de manifiesto ${ }^{47}$ la manera en que la prevalencia en el mundo académico del llamado Modelo Estándar de Ciencia Social ha contribuido a construir y mantener muchas de las distorsiones cognitivas hoy existentes, y en particular al sostenimiento del mito de la tabla rasa y del mito del buen salvaje, como consecuencia del a priori igualitarista y culturalista con que generalmente se abordan todos los fenómenos 
sociales (¡y naturales!). En el mismo sentido, Alain Finkielkraut ${ }^{48}$ se escandalizaba de la abducción que parecían haber experimentado numerosos filósofos y científicos sociales por parte de ese Modelo Estándar que apriorísticamente omite o condena cualquier aportación científica que no pase por las horcas caudinas del culturalismo políticamente correcto, a pesar del gigantesco retroceso para el saber que ello supone.

La sociología del conocimiento, en fin, con sus múltiples elementos constituyentes y conexiones con otras disciplinas, nos ha parecido una herramienta especialmente útil para dar cuenta y tratar de explicar sucintamente los procesos que hacen que una distorsión cognitiva se instale satisfactoriamente en la concepción del mundo de una sociedad o de amplios grupos sociales y en la mentalidad particular de los individuos como saber social objetivado, hasta constituirse eventualmente como pensamiento dominante.

Es condición indispensable, sin embargo, para que esta rama de la sociología alcance sus objetivos científicos, que ella misma esté libre de afecciones ideológicas; no se puede estudiar la distorsión cognitiva a partir de una distorsión cognitiva. Conviene, como sabemos, que la ciencia social esté exenta de contaminaciones culturales, políticas, económicas o de otra índole si se quiere ciencia y no mera sirvienta de ideologías. Parece que en este sentido el respetar la Ley de Hume ${ }^{49}$ y el principio weberiano de neutralidad axiológica constituyen una acertada práctica, pero probablemente baste con seguir el criterio de falsabilidad popperiano para, si no alcanzar la verdad, poner al menos de relieve la mentira, desenmascararla. Y no es ésta, pensamos, pequeña contribución al desarrollo de nuestro conocimiento científico del mundo social: como nos recordaba $\operatorname{Berger}^{50}$, el genio de la sociología es negativo, como el Mefistófeles de Goethe, un espíritu que siempre dice "no".

\section{NOTAS}

1 Véase, por ejemplo: J.M. Cocom Pech, en www.cerigua.org/portal/Article7580.html [consultado en febrero de 2007]; Rigoberta Menchú, en

http://www.elpais.com/articulo/cine/Vientos/tormenta/Apocalypto/elpepuculcin/20070119elpepi cin_7 [consultado en febrero de 2007]; Guillermo Paz, "Apocalypto", en

http://democraciamulticultural.blogspot.com/2007/01/apocalypto.html [consultado en febrero de 2007]; cfr. Navajas, S. "El Apocalipsis según Mel Gibson”, en

http://findesemana.libertaddigital.com/articulo.php/1276232936 [consultado en febrero de 2007]

${ }^{2}$ La palabra "Zuma" proviene al parecer del nombre de la playa donde se desarrollaron los ensayos de Neil Young con el grupo Crazy Horse durante la grabación del disco. Nada que tenga que ver, por consiguiente, con Moctezuma

${ }^{3}$ Otras películas que pueden citarse, que tocan el tema con y sin la presencia de conquistadores, son: "Los reyes del sol", de J. Lee Thomson, 1963); "El imperio del sol" (Royal hunt of the sun), de Irving Lerner (1969); "O No Coronado", de Craig Baldwin (1992). Se prepara actualmente otra película, que llevará el título de "El conquistador", en la que A. Banderas encarnará a Hernán Cortés 
${ }^{4}$ Cortez es la segunda canción más votada por sus fans de todas las compuestas por Young (su discografía abarca más de 40 títulos); véase: http://hyperrust.org/Rust/SongPoll98.html [consultado en diciembre de 2006]

${ }^{5}$ Véase CASADO SOTO, J.L. (1988): Los barcos españoles del siglo XVI y la Gran Armada, Madrid, San Martín; RUBIO SERRANO, J.L. (1991): Arquitectura de las naos y galeones de las flotas de Indias, Málaga, Seyer; KIRSCH, P. (1990): The galleon: the great ships of the Armada era, London, Conway Maritime Press; FERNÁNDEZ GONZÁLEZ, F. "El galeón español”, en www.etsin.upm.es/agenda acad/archivos.php3?num=806 [consultado en diciembre de 2006]

${ }^{6}$ THOMAS, H. (1994): La conquista de México, Barcelona, Planeta, p. 184

7 MADARIAGA, S. (1995): Hernán Cortés, Madrid, Planeta-De Agostini, pp. 122-133; BABELON, J. (1988): Hernán Cortés, Madrid, Aguilar, pp. 7-27; MIRALLES, J. (2003): Hernán Cortés: inventor de México, Madrid, ABC, pp. 579-596; y especialmente RAMOS, D. (1992): Hernán Cortés: mentalidad y propósitos, Madrid, Rialp, pássim

${ }^{8}$ Bernal Díaz del Castillo utiliza en su Historia verdadera de la conquista de la Nueva España (Madrid, Espasa Calpe, 2000, pássim -escrita en 1555 y publicada por primera vez en 1632-) la palabra "Montezuma", pero es harto improbable que Young conozca siquiera al autor y su obra

${ }^{9}$ Véase, por ejemplo, la Primera Carta de Relación del propio Cortés, en la que se describen los tesoros que éste envía al emperador Carlos V: CORTÉS, H. (2000): Cartas de Relación, Madrid, Dastin, pp. 75-81. Véase también otra descripción de tesoros aztecas conseguidos en la Segunda Carta: CORTÉS, Ibid., pp. 136-137

${ }^{10}$ THOMAS, H. op. cit., pp. 211 ss. Cfr. MIRALLES, op. cit., pp. 110ss y $125 \mathrm{ss}$

${ }^{11}$ THOMAS, op. cit., p. 59, cfr. MIRALLES, op. cit., p. 251, donde se relata que en la batalla de Otumba "las faldas del monte albeaban con las túnicas de la multitud de indios que descendían (...). Entre aquella marea (de indios) vestida de blanco, destacaban puntos de colores muy vivos. Eran los penachos de los capitanes"

${ }^{12}$ Según la Comisión Nacional para el Desarrollo de los Pueblos Indígenas (CDI), organismo oficial mexicano, existen hoy en México unos doce millones de indios "puros" y el $60 \%$ aproximadamente de la población mexicana es mestiza (www.cdi.gob.mx/index.php?id $\underline{\text { seccion }=3}$ [consultado en febrero de 2007]). Compárese este dato, a título ilustrativo del presunto genocidio llevado a cabo por los españoles en América, con el que nos proporciona la Oficina del Censo de los Estados Unidos de América: en 2000 había en EE.UU. 2.475.956 indios "puros" (la mitad de los cuales en Alaska) y 4.119 .301 mestizos (http://factfinder.census.gov/servlet/ DatasetMainPageServlet [Consultado en febrero de 2007])

${ }^{13}$ THOMAS, op. cit., pp. 42-43

${ }^{14}$ MIRALLES, pp. 191 y 337-338; MADARIAGA, op. cit., pp. 19-20; THOMAS, op. cit., p. 50

${ }^{15}$ THOMAS, op. cit., pp. 28 y 33 ss

${ }^{16}$ MIRALLES, op. cit., p. 148; THOMAS, op. cit., p. 34

${ }^{17}$ THOMAS, op. cit., p. 33

${ }^{18}$ ID., Ibid., p. 35

${ }^{19}$ BENSON, E.P. y BOONE, E. H. (1986): "Ritual human sacrifice in Mesoamerica”, American Antiquity, vol. 51, 1: pp. 99-200; cfr. SCHELE, L. y FREIDEL, D. (1999): Una selva de reyes. La asombrosa historia de los antiguos mayas, México, Fondo de Cultura Económica; RIVERA DORADO, M. (2005): "Catorce tesis sobre la religión maya", Revista de Antropología Americana, 35: pp. 7-32

${ }^{20}$ THOMAS, op. cit., pp. 61-62

${ }^{21}$ RAMOS, D. (1998): Genocidio y conquista: viejos mitos que siguen en pie, Madrid, Real Academia de la Historia, pp. 159 y 168; MADARIAGA, op. cit., pp. 20-21; THOMAS, op. cit., pp. $50-51$ 
${ }^{22}$ BENNASSAR, B. (2002): Hernán Cortés. El conquistador de lo imposible, Madrid, Temas de Hoy, especialmente capítulo III; cfr. BABELON, op. cit., esp. Cap. III; MIRALLES, op. cit., pp. 172ss ${ }^{23}$ MADARIAGA, op. cit., p. 447ss; BABELON, op. cit., p. 228; BENNASSAR, op. cit., pp. 274-275; THOMAS, op. cit., p. 584. El propio Cortés en su Tercera Carta de relación se expresa en términos muy compasivos hacia los mexicas: CORTÉS, op. cit., pp. 275-278

${ }^{24}$ THOMAS, op. cit., p. 74; cfr. MADARIAGA, op. cit., pp. 23-24

${ }^{25}$ PINKER, S. (2003): La tabla rasa, Paidós, Barcelona, pp. 21-35

${ }^{26}$ GIRARD, R. (1986): El chivo expiatorio, Barcelona, Anagrama; ALLPORT, G. (1977): La naturaleza del prejuicio, Buenos Aires, Eudeba; cfr. DOVIDIO, P.G. y RUDMAN, L.A. (eds.), (2005): On the nature of prejudice: fifty years after Allport, Malden, Blackwell

${ }^{27}$ THOMAS, W.I. (1928): The child in America: Behavior problems and programs, Knopf, New York, especialmente p. 572, donde se encuentra el famoso teorema: "If men define situations as real, they are real in their consequences"

${ }^{28}$ FESTINGER, L. (1982): Teoría de la disonancia cognoscitiva, Madrid, Instituto de Estudios Políticos

${ }^{29}$ NIETZSCHE, F. (1971): La genealogía de la moral, Madrid, Alianza; WEBER, M., (2000): Ensayos sobre sociología de la religión, Madrid, Taurus

${ }^{30}$ SARTRE, J. P. (1969): El ser y la nada, Buenos Aires, Losada

${ }^{31}$ VACA DE OSMA, J. A. (2000): Hernán Cortés, Madrid, Espasa-Calpe; véase también VACA DE OSMA, J.A. (2004): El imperio y la leyenda negra, Madrid, Rialp

${ }^{32}$ Los conceptos fundamentales de la sociología del conocimiento de Peter Louis Berger se hallan en BERGER, P. L. y LUKCMANN, T. (1968): La construcción social de la realidad, Buenos Aires, Amorrortu, y también en BERGER, P. L. (1971): Para una teoría sociológica de la religión, Buenos Aires, Kairós. Para un estudio detallado de la sociología del conocimiento bergeriana puede verse PALACIOS GÓMEZ, J. L. (1991): La sociología del conocimiento en P.L. Berger, Madrid, Universidad Complutense de Madrid

${ }^{33}$ BERGER, Para una teoría ., p. 15. En general, BERGER, P.L. y LUCKMANN, T. La construcción..., especialmente capítulos II y III

${ }^{34}$ BERGER, P. L. y LUCKMANN, T. op. cit., pp. 197ss. Para otra aproximación complementaria al fenómeno de la alternación, véase: BERGER, P. L. (1977): Introducción a la sociología, México, Limusa, pp. 77-80 y 81ss

${ }^{35}$ Véase VATTIMO, G. y ROVATTI, P. A. (eds.) (2003), El pensamiento débil, Madrid, Cátedra, donde se tratan las cuestiones de la postmodernidad, el relativismo y la multiculturalidad como elementos constituyentes de esta forma de "pensamiento"

${ }^{36}$ Para la definición bergeriana de "paquete", véase BERGER, P. L. BERGER, B. y KELLNER, H. Un mundo sin hogar. Modernización y conciencia, Santander, Sal Terrae, p. 86. Este concepto está inspirado en la sociología de la educación de Illich: ILLICH, I. (1985): La sociedad desescolarizada, Barcelona, Barcal, esp. cap. III

${ }^{37}$ Para la definición bergeriana de "portador", véase asimismo BERGER, P. L. BERGER, B. y KELLNER, H. Un mundo., p. 86

${ }^{38}$ No es una cuestión menor que ese discurso se establezca como definición del mundo gracias a que es compartida por mucha gente. Como dice Berger: "Una de las tesis fundamentales de la sociología del conocimiento es la que afirma que la plausibilidad de las interpretaciones de la realidad depende del soporte social que éstas presentan. Dicho más simplemente, obtenemos nuestras ideas sobre el mundo originariamente de otras personas, y esas ideas siguen siendo admisibles para nosotros, en buena medida, porque los demás las sostienen", en BERGER, P. L. Rumor de ángeles. La sociedad moderna y el descubrimiento de lo sobrenatural, Barcelona, Herder, p. 67 
${ }^{39}$ A este mecanismo de "protección ideológica" se refiere Revel cuando alude a la "resistencia ante la información": véase REVEL, J. F. (2006): El conocimiento inútil, Madrid, Espasa-Calpe, pp. 28-31

${ }^{40}$ MANNHEIM, K. (1962): Ideología y utopía, Madrid, Aguilar

${ }^{41}$ ALTHUSSER, L. (1974): Ideología y aparatos ideológicos del estado, Buenos Aires, Nueva Visión

${ }^{42} \mathrm{La}$ importancia de esta alianza se pone de relieve en el relato de los hechos que contiene cualquiera de las obras sobre Cortés o la conquista de México aquí consideradas. La amistad de los jefes tlaxcaltecas Maxixcatzin y Xicoténcatl el Viejo resultó efectivamente decisiva (especialmente después de la huida de Tenochtitlan en 1520). Tampoco fueron amistades menores las de Quauhtlaebana (el "cacique gordo" de Cempoala) y, desde luego, la de Malinalli (la imprescindible intérprete de Cortés)

${ }^{43}$ Tal vez en competencia con la Reconquista, que un periodista tan notable y afamado como J.L. Cebrián, Consejero Delegado del grupo de comunicación Prisa, ha calificado como "insidiosa" en su artículo "Barbarie, religión y progreso" (El País, 17.09.06). Para una robusta refutación de esta idea véase FANJUL, S. (2004): La quimera de Al-Andalus, Madrid, Siglo XXI

${ }^{44}$ SCHUTZ, A. (1974): El problema de la realidad social, Buenos Aires, Amorrortu, pp. 215 y ss.; cfr. SCHUTZ, A. y LUCKMANN, T. (1977): Las estructuras del mundo de la vida, Buenos Aires, Amorrortu, pp. $41 \mathrm{ss}$

${ }^{45}$ GLUCKSMANN, A. (2004): Occidente contra Occidente, Madrid, Taurus

${ }^{46}$ BERGER, P.L. y LUCKMANN, T. La construcción ..., pp. 124-125

${ }^{47}$ PINKER, S. (2000), Cómo funciona la mente, Barcelona, Destino, pp. 68-73; cfr. PINKER, La tabla ..., pp. 112-115

${ }^{48}$ FINKIELKRAUT, A. (1990), La derrota del pensamiento, Barcelona, Anagrama

${ }^{49}$ Nos referimos, por supuesto, a una de las tesis esenciales del empirismo ético de Hume: el error que constituye derivar del plano del ser (los hechos) el del deber ser (los valores). Véase HUME, D. (1977): Tratado sobre la naturaleza humana, Madrid, Editora Nacional, pp. 496-497. Para un comentario crítico de este principio, véase HERRERA, M. (2005): Metateoría de las ciencias sociales. El puzzle epistemológico, Madrid, Tecnos, pp. 86-100

50 BERGER, P.L., BERGER, B. y KELLNER, H. Un mundo, p. 222. El carácter "desenmascarante" de la sociología impregna toda la obra bergeriana: cfr. BERGER, P.L. y KELLNER, H. (1985): La reinterpretación de la sociología: ensayo sobre el método y la vocación sociológicos, Madrid, Espasa-Calpe, pp. 39-40. 